\title{
New Insights into the Interaction between Graphene Oxide and Beta-Blockers
}

\author{
Yuehua Deng ${ }^{1,2, *}$, Yani Li ${ }^{1,2}$, Wenjie Nie ${ }^{1,2}$, Xiang Gao ${ }^{1,2}$, Shentan Liu ${ }^{1,2}$, Xiaochun Tan ${ }^{1}$, \\ Mingming Chen ${ }^{1}$ and Dongzhuang Hou ${ }^{1,2}$ \\ 1 College of Geology and Environment, Xi'an University of Science and Technology, Xi'an 710054, China; \\ ynli2019@163.com (Y.L.); nwj@xust.edu.cn (W.N.); gaoxiang@iccas.ac.cn (X.G.); liushentan@seu.edu.cn (S.L.); \\ txc9150@163.com (X.T.); 13720599719@163.com (M.C.); houdongzhuang0207@163.com (D.H.) \\ 2 Shaanxi Provincial Key Laboratory of Geological Support for Coal Green Exploitation, Xi'an 710054, China \\ * Correspondence: yhdeng2018@xust.edu.cn
}

Received: 17 July 2019; Accepted: 27 September 2019; Published: 9 October 2019

check for updates

\begin{abstract}
As a nano-adsorbent, magnetic graphene oxide $\left(\mathrm{GO} / \mathrm{Fe}_{3} \mathrm{O}_{4}\right)$ was synthesized to potentially adsorb propranolol (PRO) from water. The synthetic material was characterized by SEM, TEM, VSM, FTIR, XRD, zeta potential, and XPS. The environmental factors, such as $\mathrm{pH}$, humic acid concentration, PRO concentration, and contact time, were investigated regarding their effect on the adsorption process. The kinetics data fitted the pseudo first-order and second-order kinetics equations. The Langmuir equation, the Freundlich equation, and the Sips equation were used to analyze the adsorption isotherms. Electrostatic attraction, hydrogen bonding, and the $\pi-\pi$ interaction all contributed to the adsorption process of PRO onto $\mathrm{GO} / \mathrm{Fe}_{3} \mathrm{O}_{4}$. The discovery of this study emphasized the feasibility of $\mathrm{GO} / \mathrm{Fe}_{3} \mathrm{O}_{4}$ removal of $\mathrm{PRO}$ and expanded the scope of the application of GO.
\end{abstract}

Keywords: magnetic graphene oxide; propranolol; $\mathrm{Fe}_{3} \mathrm{O}_{4}$; adsorption

\section{Introduction}

Graphene, as a member of the group of carbon materials, has attracted enormous attention from researchers since 2004 due to its excellent mechanical and physicochemical properties [1]. As its derivative, graphene oxide (GO) exhibits superior properties. Both $\mathrm{GO}$ and graphene have two-dimensional, sheet-like structures which are connected by carbon atoms through the hybridization of $\mathrm{sp}^{2}$ and $\sigma$ bonds to the surrounding carbon atoms to form a hexagonal honeycomb lattice [2-4]. Compared with graphene, $\mathrm{GO}$ has a large number of oxygen-containing functional groups at the edges and inside of the sheet, including hydroxyl groups, carbonyl groups, carboxyl groups, and epoxy groups, which allows GO to be operatively bonded to organic pollutants [5-7]. Therefore, GO is often used as an adsorbent in wastewater treatment.

The environmental residue of pharmaceutical and personal care products (PPCPs) has received increasing attention worldwide [8,9]. As a new type of pollutant, propranolol (PRO) is a beta-blocker for the treatment of cardiovascular disease [10]. After entering the water body as a parent compound, it cannot be completely removed by the traditional sewage treatment process [11,12]. Toxicity tests indicated that PRO remaining in water can cause damage to aquatic organisms and even harm human health [13-16]. Kyzas et al. studied the removal of PRO and atenolol from water by GO adsorption [17]. The results showed that the oxygen-containing functional groups on the surface of GO can effectively remove atenolol and PRO from water via electrostatic interaction and hydrogen bonding. However, the presence of these groups on the surface of GO has a double-sided effect. It is easily bonded to contaminants, but it is difficult for GO to be separated from water bodies due to the hydrophilicity of 
these groups $[18,19]$. After the adsorption process completes, it must be separated from the aqueous solution via filtration or centrifugation, which is complicated, time-consuming, and costly.

Magnetic separation is an effective way to solve this problem. Magnetic nanoparticles have received extensive attention due to their unique magnetic properties. A specific external magnetic field is applied, the magnetic material can be separated according to a specific path. The magnet disappears and the material can be easily dispersed into the solution again when the applied magnetic field is removed [20,21]. Based on this advantage, combining $\mathrm{Fe}_{3} \mathrm{O}_{4}$ with $\mathrm{GO}$ not only preserves the high adsorption capacity of $\mathrm{GO}$, but also allows it to be quickly separated from water. It is worth mentioning that the loading of $\mathrm{Fe}_{3} \mathrm{O}_{4}$ particles makes the GO sheets less prone to aggregation, which is due to the presence of van der Waals forces between the GO layers [22,23]. Miao et al. showed that $\mathrm{GO} / \mathrm{Fe}_{3} \mathrm{O}_{4}$ has a high adsorption capacity for adsorbing tetracyclines [24]. He et al. formed $\mathrm{GO}-\mathrm{Fe}_{3} \mathrm{O}_{4}$ hybrid by covalent bonding to adsorb methylene blue and neutral red cationic dyes with a high adsorption capacity [25]. Huang et al. studied the adsorption of tetracycline, $\mathrm{Cd}$, and arsenate $(\mathrm{As}(\mathrm{V}))$ on graphene oxide when they coexist, and the excellent property of $\mathrm{GO} / \mathrm{Fe}_{3} \mathrm{O}_{4}$ was mainly attributed to its high dispersibility, thin nanosheets and various functional groups [26]. The above researches indicated the possibility of using magnetic GO in the field of wastewater treatment in the future. As far as is known, however, there has been no literature on the removal of $\mathrm{PRO}$ from water by $\mathrm{GO} / \mathrm{Fe}_{3} \mathrm{O}_{4}$.

In this study, $\mathrm{GO}$ was prepared using the modified Hummers method and $\mathrm{GO} / \mathrm{Fe}_{3} \mathrm{O}_{4}$ was further synthesized in a one-step reaction. PRO was chosen as the target contaminant. The factors affecting PRO adsorption were systematically investigated, and the adsorption kinetics and adsorption isotherms for PRO were studied in detail. The objectives of this study were as follows: (1) prepare $\mathrm{GO} / \mathrm{Fe}_{3} \mathrm{O}_{4}$ magnetic composites, (2) study the adsorption behavior of $\mathrm{PRO}$ onto $\mathrm{GO} / \mathrm{Fe}_{3} \mathrm{O}_{4}$, and (3) discuss the possible adsorption mechanisms of this process.

\section{Materials and Methods}

\subsection{Materials}

Propranolol hydrochloride used in the experiment was purchased from Aladdin Reagent Co., Ltd. (Shanghai, China). Graphite powder was supplied by Guangdong Xilong Chem. Co. Ltd. (Shantou, China). The formic acid and acetonitrile were of HPLC grade. All other reagents, including humic acid (HA) and ferrous sulfate heptahydrate $\left(\mathrm{FeSO}_{4} \cdot 7 \mathrm{H}_{2} \mathrm{O}\right)$, were analytical grade and used without any further purification. All solutions were prepared using distilled water.

\subsection{Preparation of $\mathrm{GO} / \mathrm{Fe}_{3} \mathrm{O}_{4}$}

The preparation method of the material referred to our previous research [27].

Preparation of GO: $1 \mathrm{~g}$ each of potassium sulfate, phosphorus pentoxide, and graphite powder were vigorously stirred in $10 \mathrm{~mL}$ of concentrated sulfuric acid and kept at $80{ }^{\circ} \mathrm{C}$ for $5 \mathrm{~h}$. It was then washed with distilled water to a neutral $\mathrm{pH}$ and dried at $60^{\circ} \mathrm{C}$ in a vacuum oven. Potassium permanganate $(4 \mathrm{~g})$ and the above product were dissolved into concentrated sulfuric acid $(40 \mathrm{~mL})$ placed in an ice bath. After keeping at $35^{\circ} \mathrm{C}$ for $2 \mathrm{~h}$, distilled water $(100 \mathrm{~mL})$ was slowly added to the mixture, and the mixture was heated to $98^{\circ} \mathrm{C}$ for $15 \mathrm{~min}$. Hydrogen peroxide was added to neutralize excess potassium permanganate until the solution was a golden yellow. After settling, the supernatant was decanted, and the precipitant was washed with dilute hydrochloric acid and distilled water to a neutral $\mathrm{pH}$. Finally, the mixture was dried at $60^{\circ} \mathrm{C}$ and passed through a 200-mesh screen.

Preparation of $\mathrm{GO} / \mathrm{Fe}_{3} \mathrm{O}_{4}: \mathrm{GO}(0.5 \mathrm{~g})$ was dispersed into deionized water and sonicated for $30 \mathrm{~min}$. Then, the mixture was kept in a $\mathrm{N}_{2}$ atmosphere for $15 \mathrm{~min}$. Ferrous sulfate heptahydrate $(2 \mathrm{~g})$ was added to the above solution under $\mathrm{N}_{2}$ bubbling at $90{ }^{\circ} \mathrm{C}$. The mixture was labeled as solution $\mathrm{A}$. Sodium hydroxide $(1.8 \mathrm{~g})$ and sodium nitrate $(0.9 \mathrm{~g})$ were dissolved in distilled water $(40 \mathrm{~mL})$, and the solution was marked as solution B. Solution B was added dropwise to solution A under $\mathrm{N}_{2}$ bubbling. 
Then, the final mixture was kept at $90{ }^{\circ} \mathrm{C}$ for $4 \mathrm{~h}$. After being cooled to room temperature, it was washed to a neutral $\mathrm{pH}$, dried at $60^{\circ} \mathrm{C}$, and passed through a 100-mesh screen.

\subsection{Characterization of $\mathrm{GO} / \mathrm{Fe}_{3} \mathrm{O}_{4}$}

The surface topography and structure of the prepared materials were observed using SEM (JEOL, Tokyo, Japan) and TEM (FEI-JSM 6320F, JEOL, Tokyo, Japan). The magnetic property of the material was measured using VSM (Lake Shore, USA) at room temperature. The key functional groups of the adsorbent were analyzed using FTIR (Thermo Electron Nicolet-360, USA). The XRD patterns of material were conducted to determine the crystal structure with X-ray diffractometer (ARL Co., Switzerland) at the range of $5^{\circ}$ to $90^{\circ}$. The surface charge of the adsorbent was measured at various $\mathrm{pH}$ values using the zeta potential (Malvern Instrument Co., U.K.). The surface elements of the adsorbent were analyzed using XPS.

\subsection{Batch Experiments}

All experiments were conducted to evaluate the adsorption performance of $\mathrm{GO} / \mathrm{Fe}_{3} \mathrm{O}_{4}$ at $30{ }^{\circ} \mathrm{C}$. The amount of PRO stock solution $(1 \mathrm{~g} / \mathrm{L})$ was added into the centrifuge tube with $0.01 \mathrm{~g}$ adsorbent. The effects of adsorption time, the concentration of $\mathrm{PRO}, \mathrm{pH}$, and the concentration of humic acid (HA) were studied in turn. The $\mathrm{pH}$ of the reaction system was adjusted using $0.1 \mathrm{~mol} / \mathrm{L} \mathrm{NaOH}$ and $0.1 \mathrm{~mol} / \mathrm{L}$ $\mathrm{HCl}$ solutions. The mixtures were shaken for a given time. The solution passed through a $0.22 \mu \mathrm{m}$ filter with a syringe after equilibrium. The initial and final concentrations of PRO were measured by HPLC at a wavelength of $290 \mathrm{~nm}$. The adsorption capacity was determined using Equation (1):

$$
q_{e}=\frac{\left(C_{0}-C_{e}\right) V}{m}
$$

where $C_{0}(\mathrm{mg} / \mathrm{L})$ and $C e(\mathrm{mg} / \mathrm{L})$ are the initial and equilibrium concentrations of PRO. $q_{e}(\mathrm{mg} / \mathrm{g})$ is the adsorption capacity of $\mathrm{GO} / \mathrm{Fe}_{3} \mathrm{O}_{4} . V(\mathrm{~L})$ is the volume of the solution and $m(\mathrm{~g})$ represents the mass of $\mathrm{GO} / \mathrm{Fe}_{3} \mathrm{O}_{4}$.

\section{Results and Discussion}

\subsection{Characterization of $\mathrm{GO} / \mathrm{Fe}_{3} \mathrm{O}_{4}$}

In order to study the morphological and microstructural details of $\mathrm{GO} / \mathrm{Fe}_{3} \mathrm{O}_{4}, \mathrm{SEM}$ images of $\mathrm{GO}$ and $\mathrm{GO} / \mathrm{Fe}_{3} \mathrm{O}_{4}$ were conducted and presented in Figure 1a,b. A TEM image of $\mathrm{GO} / \mathrm{Fe}_{3} \mathrm{O}_{4}$ was shown in Figure 1c. 

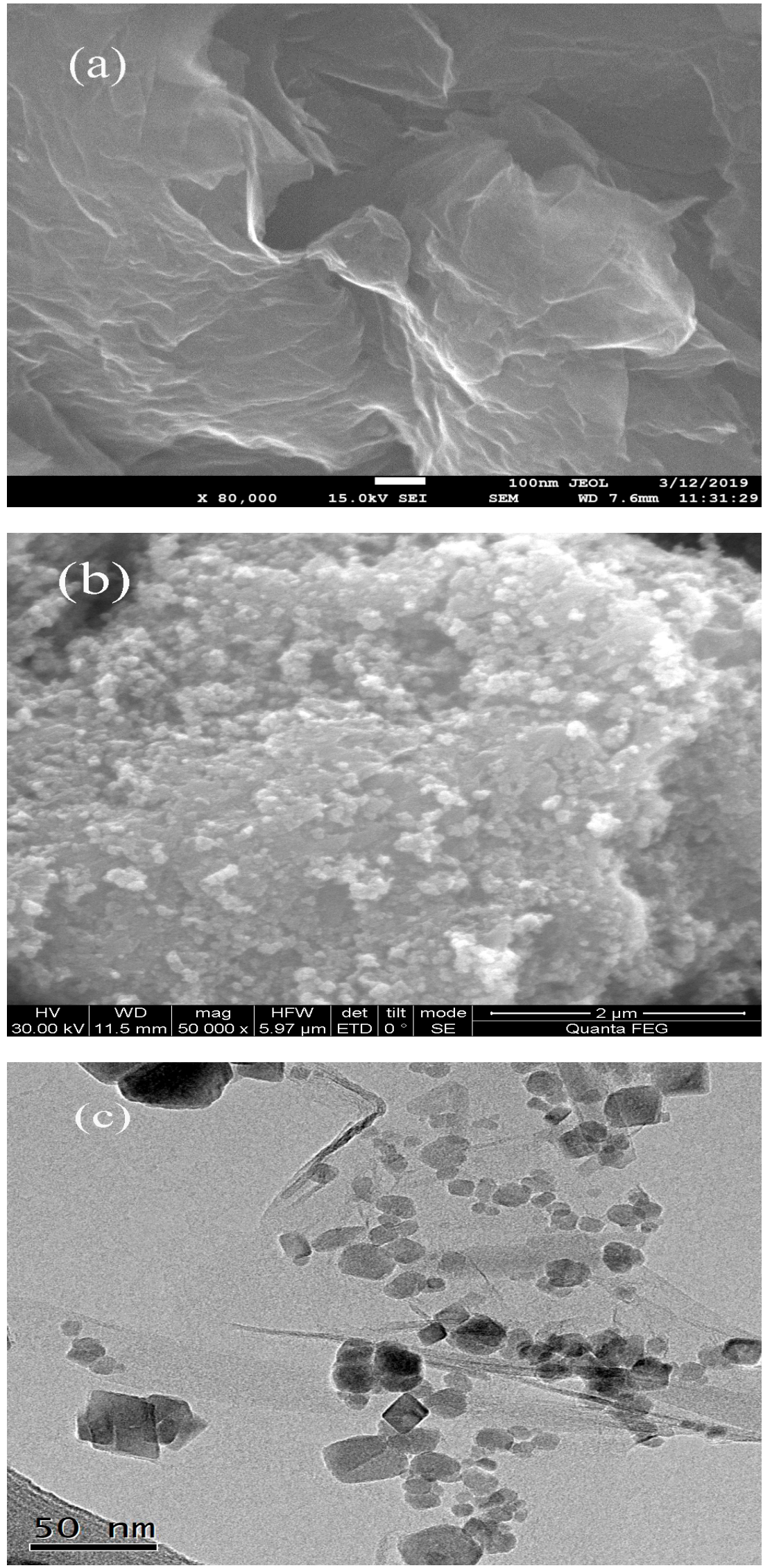

Figure 1. SEM images of $\mathrm{GO}(\mathbf{a})$ and $\mathrm{GO} / \mathrm{Fe}_{3} \mathrm{O}_{4}(\mathbf{b})$, and TEM image of $\mathrm{GO} / \mathrm{Fe}_{3} \mathrm{O}_{4}$ (c). 
As shown in Figure 1a, GO exhibited a sheet-like structure with a smooth surface and edges, which was consistent with that described in previous reports. Partial aggregation can also be observed due to the existence of oxygen-containing functional groups on the GO sheet. Figure $1 \mathrm{~b}$ showed the successful formation of the compound. It can be seen that the GO was the basal plane of prepared material and $\mathrm{Fe}_{3} \mathrm{O}_{4}$ particles were uniformly distributed and attached on the surface of GO. The formation of the $\mathrm{GO} / \mathrm{Fe}_{3} \mathrm{O}_{4}$ did not cause damage to the structure of $\mathrm{GO}$ and $\mathrm{GO}$ maintained its original morphology, which suggested that $\mathrm{GO} / \mathrm{Fe}_{3} \mathrm{O}_{4}$ still kept the unique properties of $\mathrm{GO}$ while being quickly recycled due to the presence of $\mathrm{Fe}_{3} \mathrm{O}_{4}$ particles. Some wrinkles were observed on the $\mathrm{GO}$ surface and provided a larger surface area for the successful loading of $\mathrm{Fe}_{3} \mathrm{O}_{4}$ particles, preventing from the aggregation of GO. The surface coverage of the prepared material was further identified using the TEM image (Figure 1c). It was also found that $\mathrm{Fe}_{3} \mathrm{O}_{4}$ particles (about $30 \mathrm{~nm}$ ) were loaded on the transparent and slightly aggregated GO films.

The magnetic property of $\mathrm{GO} / \mathrm{Fe}_{3} \mathrm{O}_{4}$ was researched by measuring the field-dependent magnetization curve at room temperature. As shown in Figure 2, the saturation magnetization of $\mathrm{Fe}_{3} \mathrm{O}_{4} / \mathrm{GO}$ was as high as $53.57 \mathrm{emu} / \mathrm{g}$, manifesting the high magnetic performance of the prepared material. The magnetization of $\mathrm{Fe}_{3} \mathrm{O}_{4} / \mathrm{GO}$ increased with the increase of the applied magnetic field strength and increased to a saturation value. The hysteresis loop was a smooth S-shape and coincided well without remanence magnetization, which indicated that the $\mathrm{Fe}_{3} \mathrm{O}_{4} / \mathrm{GO}$ was superparamagnetic and was easy to be collected from the adsorption process.

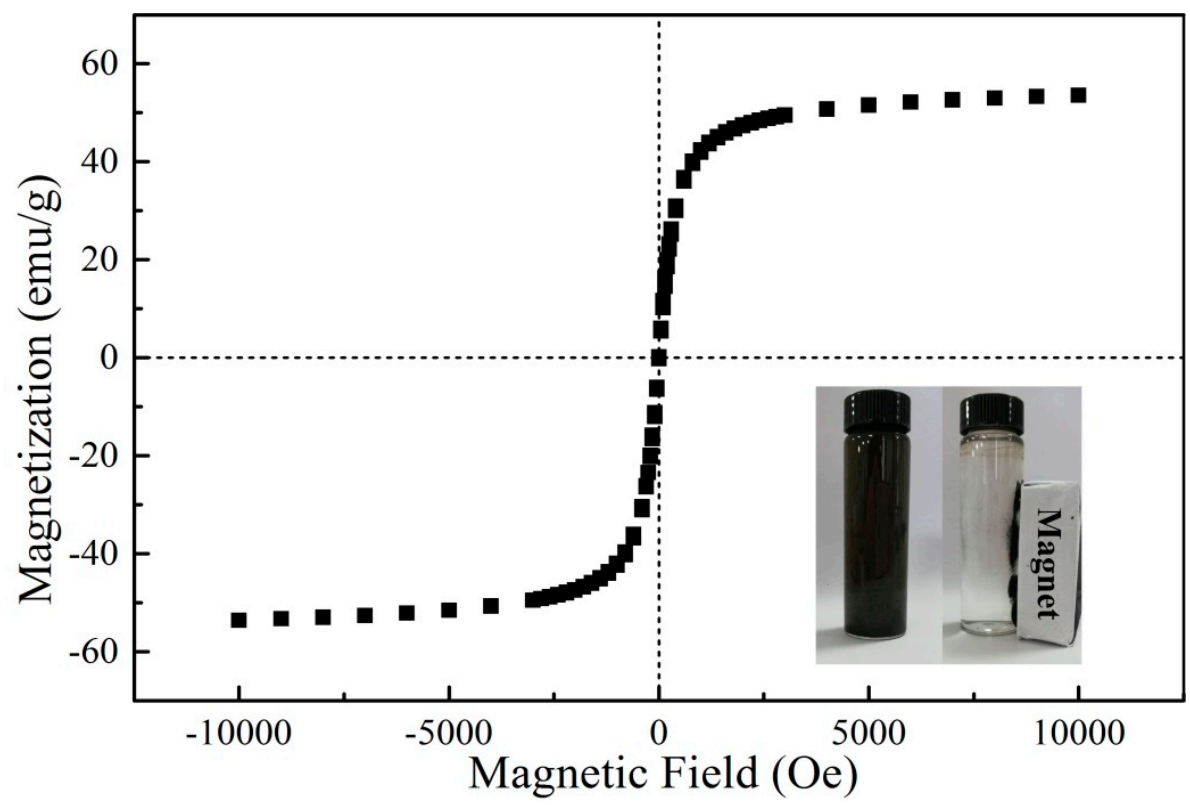

Figure 2. Magnetization curve of $\mathrm{GO} / \mathrm{Fe}_{3} \mathrm{O}_{4}$ at room temperature.

FTIR spectrum was used to identify the characteristic functional groups of $\mathrm{GO} / \mathrm{Fe}_{3} \mathrm{O}_{4}$. Figure 3 presented the FTIR of $\mathrm{GO}, \mathrm{GO} / \mathrm{Fe}_{3} \mathrm{O}_{4}$, and $\mathrm{GO} / \mathrm{Fe}_{3} \mathrm{O}_{4}$ after adsorption. In the infrared spectrum of $\mathrm{GO}$, the broad peak at $3424 \mathrm{~cm}^{-1}$ represented the $\mathrm{O}-\mathrm{H}$ stretching vibration, which formed a hydrogen bond with an oxygen atom of the adsorbed water molecule. The stretching vibration of the $\mathrm{C}=\mathrm{O}$ bond in the carboxyl group was identified via the peak at $1721 \mathrm{~cm}^{-1}$. The peak at $1622 \mathrm{~cm}^{-1}$ was associated with the stretching vibration of $C=C$ of the aromatic ring. The peaks at the $1381 \mathrm{~cm}^{-1}, 1220 \mathrm{~cm}^{-1}$, and $1051 \mathrm{~cm}^{-1}$ were attributed to the stretching vibrations of $\mathrm{C}-\mathrm{H}$ and $\mathrm{C}-\mathrm{O}$ bonds. The functional groups on the surface and edges of GO improved its hydrophilicity. Compared to the GO spectrum, some peaks had slightly changed in the spectrum of $\mathrm{GO} / \mathrm{Fe}_{3} \mathrm{O}_{4}$ due to the attachment of $\mathrm{Fe}_{3} \mathrm{O}_{4}$ particles. The weakened peak observed at $3424 \mathrm{~cm}^{-1}$ may be attributed to an increase of $\mathrm{Fe}_{3} \mathrm{O}_{4}$ and a decrease of GO in the prepared material. Another strong peak at $583 \mathrm{~cm}^{-1}$ may be due to the fact that an overlap 
occurred between a peak of GO at $582 \mathrm{~cm}^{-1}$ and the characteristic peak of $\mathrm{Fe}_{3} \mathrm{O}_{4}$ at $583 \mathrm{~cm}^{-1}$, which demonstrated that $\mathrm{Fe}_{3} \mathrm{O}_{4}$ particles were successfully loaded onto the GO. A significant vibration band formed at $1400 \mathrm{~cm}^{-1}$, which was attributed to the formation of either a monodentate complex or a bidentate complex between the carboxyl group and $\mathrm{Fe}$ on the surface of the $\mathrm{Fe}_{3} \mathrm{O}_{4}$ particles [28]. After PRO adsorption onto $\mathrm{GO} / \mathrm{Fe}_{3} \mathrm{O}_{4}$, new peaks appeared at $1105 \mathrm{~cm}^{-1}$ and $1069 \mathrm{~cm}^{-1}$, signifying the C-O-C stretching of the aryl alkyl ether in PRO. A weak peak at $2959 \mathrm{~cm}^{-1}$ was connected with N-H stretching in secondary amines of PRO. A significant peak at $1264 \mathrm{~cm}^{-1}$ represented the formation of hydrogen band between the oxygen atom in the epoxy group and the PRO molecule.

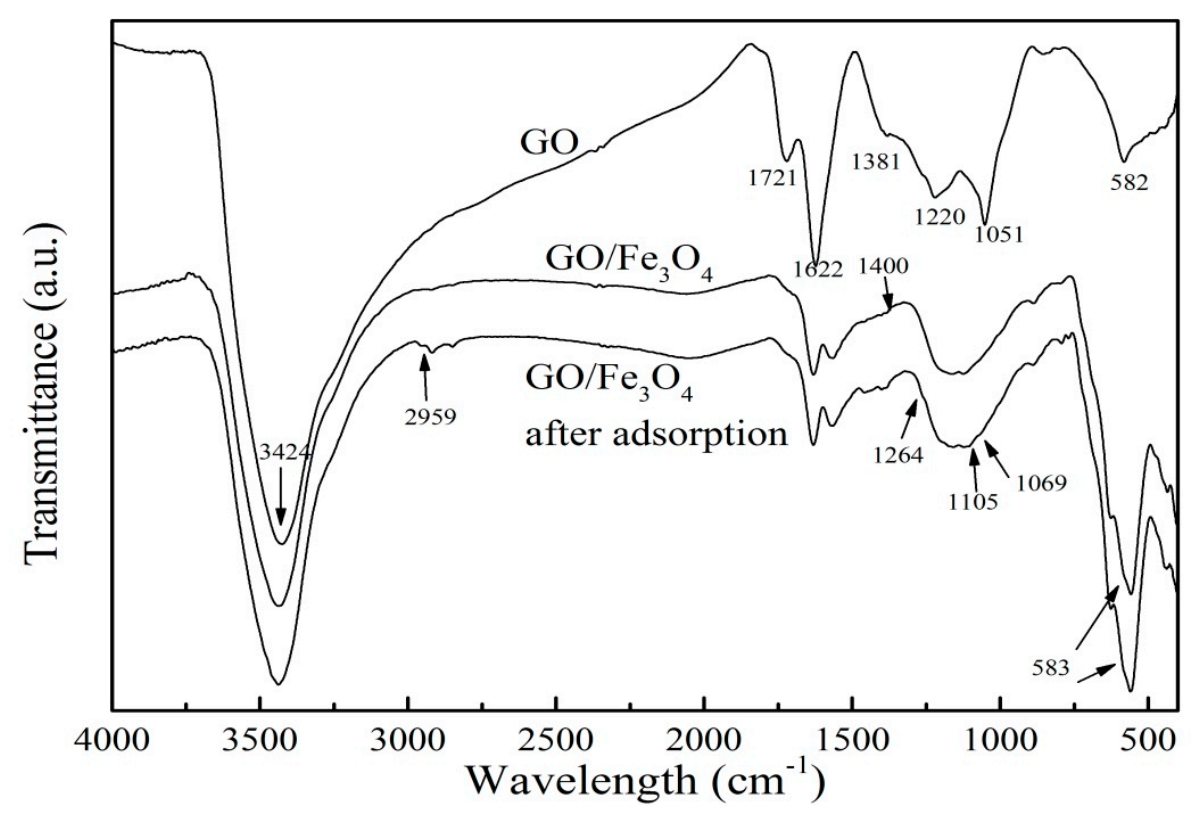

Figure 3. FTIR spectrum of $\mathrm{GO}, \mathrm{GO} / \mathrm{Fe}_{3} \mathrm{O}_{4}$, and $\mathrm{GO} / \mathrm{Fe}_{3} \mathrm{O}_{4}$ after adsorption.

Figure 4 displayed the XRD patterns of $\mathrm{GO}, \mathrm{GO} / \mathrm{Fe}_{3} \mathrm{O}_{4}$, and $\mathrm{GO} / \mathrm{Fe}_{3} \mathrm{O}_{4}$ after adsorption. For the GO pattern, a sharp diffraction peak at $10.8^{\circ}$ was observed, manifesting the presence of residual stacked layers of GO [29]. The diffraction peaks at $2 \theta$ values of $35.6^{\circ}, 43.4^{\circ}, 53.7^{\circ}$, and $62.8^{\circ}$ were consistent with the characteristic peaks of $\mathrm{Fe}_{3} \mathrm{O}_{4}$ in $\mathrm{GO} / \mathrm{Fe}_{3} \mathrm{O}_{4}$, which revealed the successful attachment of $\mathrm{Fe}_{3} \mathrm{O}_{4}$ particles. However, the sharp peak did not appear in the composite, indicating that there was a thin layer structure caused by the $\mathrm{Fe}_{3} \mathrm{O}_{4}$ particles. It can be noticed there were no significant changes after PRO adsorption, which was attributed to the fact that $\mathrm{PRO}$ adsorption caused a reduction in the relative content of $\mathrm{Fe}_{3} \mathrm{O}_{4}$ particles. 


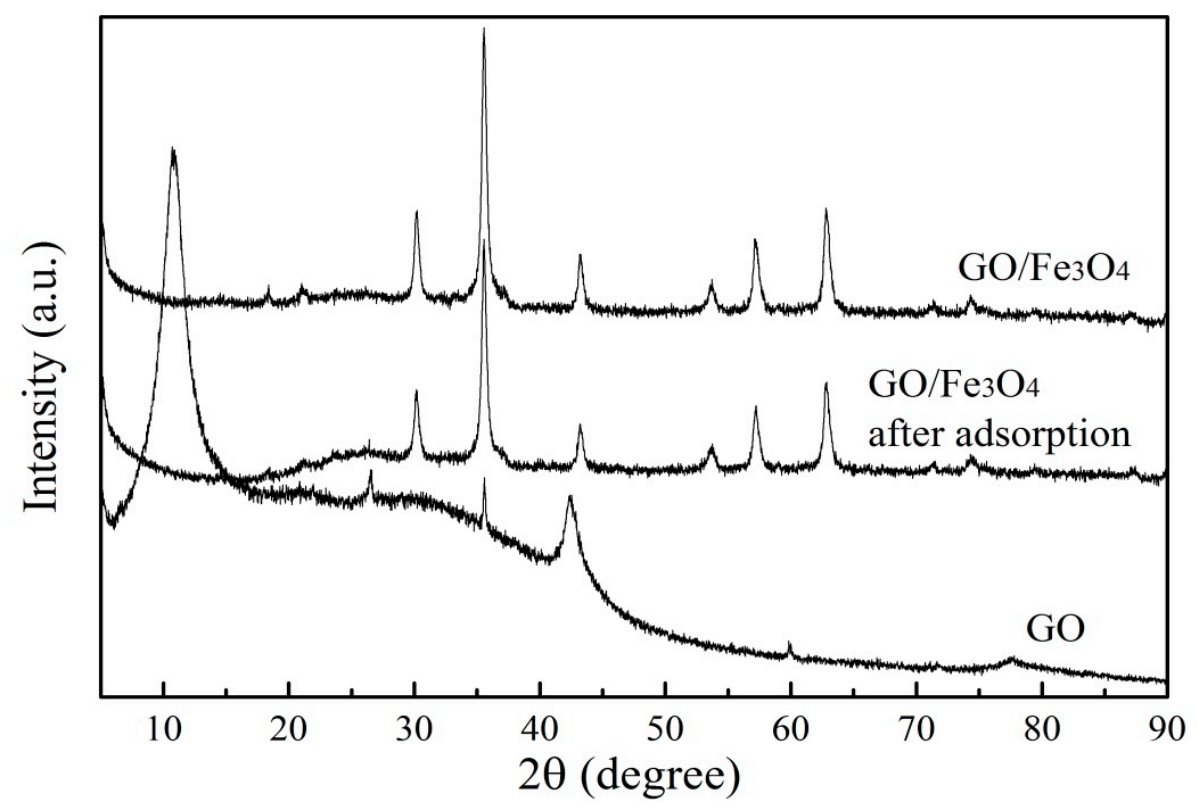

Figure 4. $\mathrm{XRD}$ of $\mathrm{GO}, \mathrm{GO} / \mathrm{Fe}_{3} \mathrm{O}_{4}$, and $\mathrm{GO} / \mathrm{Fe}_{3} \mathrm{O}_{4}$ after adsorption.

Zeta potential of $\mathrm{GO}, \mathrm{Fe}_{3} \mathrm{O}_{4}$, and $\mathrm{GO} / \mathrm{Fe}_{3} \mathrm{O}_{4}$ were exhibited in Figure 5. The zeta potential of $\mathrm{GO}$ was negative at the test $\mathrm{pH}$ range, illustrating that the surface of $\mathrm{GO}$ was charged negatively. The zero-potential point of $\mathrm{Fe}_{3} \mathrm{O}_{4}$ was about $\mathrm{pH}=6$. When $\mathrm{pH}<6$, the surface of the $\mathrm{Fe}_{3} \mathrm{O}_{4}$ was positively charged. When $\mathrm{pH}>6$, negative charges dominated on the surface of $\mathrm{Fe}_{3} \mathrm{O}_{4}$. It can be observed that the values of $\mathrm{GO} / \mathrm{Fe}_{3} \mathrm{O}_{4}$ were between $\mathrm{GO}$ and $\mathrm{Fe}_{3} \mathrm{O}_{4}$, indicating that the surface charge of $\mathrm{GO}$ was changed due to the loading of $\mathrm{Fe}_{3} \mathrm{O}_{4}$.

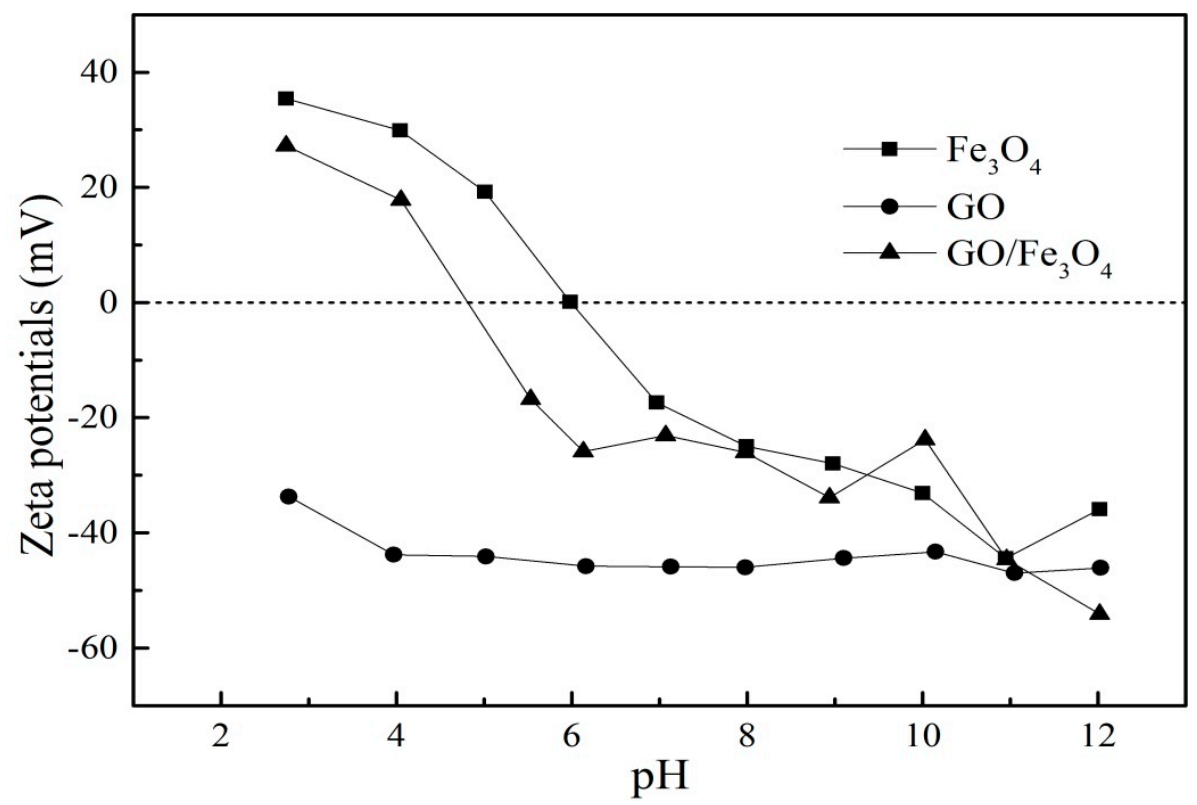

Figure 5. Zeta potential of $\mathrm{GO}, \mathrm{Fe}_{3} \mathrm{O}_{4}$, and $\mathrm{GO} / \mathrm{Fe}_{3} \mathrm{O}_{4}$.

The XPS spectra of $\mathrm{GO} / \mathrm{Fe}_{3} \mathrm{O}_{4}$ before and after the adsorption of PRO with binding energies ranging from 0 to $1400 \mathrm{eV}$ was acquired for the identification of the surface elements and performance of a quantitative analysis. It was obvious in Figure $6 \mathrm{a}$ that the peaks of $\mathrm{Fe} 2 \mathrm{p}, \mathrm{O} 1 \mathrm{~s}$, and $\mathrm{C}$ 1s were found in the full scan spectrums before and after adsorption of $\mathrm{PRO}$, which suggested the existence of $\mathrm{Fe}, \mathrm{O}$, and $\mathrm{C}$ in the $\mathrm{GO} / \mathrm{Fe}_{3} \mathrm{O}_{4}$. For the high-resolution $\mathrm{Fe} 2 \mathrm{p}$ of $\mathrm{GO} / \mathrm{Fe}_{3} \mathrm{O}_{4}$ (Figure $6 \mathrm{~b}$ ), the binding energies 
of 711.38 and $725.38 \mathrm{eV}$ corresponded to $\mathrm{Fe}^{2+}$ and $\mathrm{Fe}^{3+}$, which indicated the successful synthesis of $\mathrm{Fe}_{3} \mathrm{O}_{4}$ nanoparticles and loading onto the surface of GO. The finding was consistent with the above characterization results. From Figure $6 \mathrm{c}, \mathrm{d}$, the $\mathrm{C}=\mathrm{O}, \mathrm{C}-\mathrm{O}$, and $\mathrm{C}=\mathrm{C} / \mathrm{C}-\mathrm{C}$ characteristic bonds were present at around $284.5,285$, and $286.5 \mathrm{eV}$, respectively. It can be observed that the peak intensity of $\mathrm{C}=\mathrm{C} / \mathrm{C}-\mathrm{C}$ after adsorption became stronger than that of $\mathrm{C}=\mathrm{C} / \mathrm{C}-\mathrm{C}$ before adsorption, which was attributed to the introduction of PRO. The elemental content was given in Table 1. It can be seen that the carbon content after adsorption was significantly increased compared with before adsorption, which also indicated that PRO was successfully adsorbed onto $\mathrm{GO} / \mathrm{Fe}_{3} \mathrm{O}_{4}$. The elemental carbon contained in PRO led to an increase in the total carbon content. The successful adsorption of PRO was also illustrated by nitrogen. The content of nitrogen increased from 0.47 to 0.87 , which was caused by the amino group in PRO. At the same time, it can be seen that the content of Fe was reduced, and it was speculated that the decrease of Fe was caused by the leaching of Fe during the reaction, which was discussed in detail below. The increase in the content of other elements, especially carbon, led to a relative decrease in the proportion of oxygen.
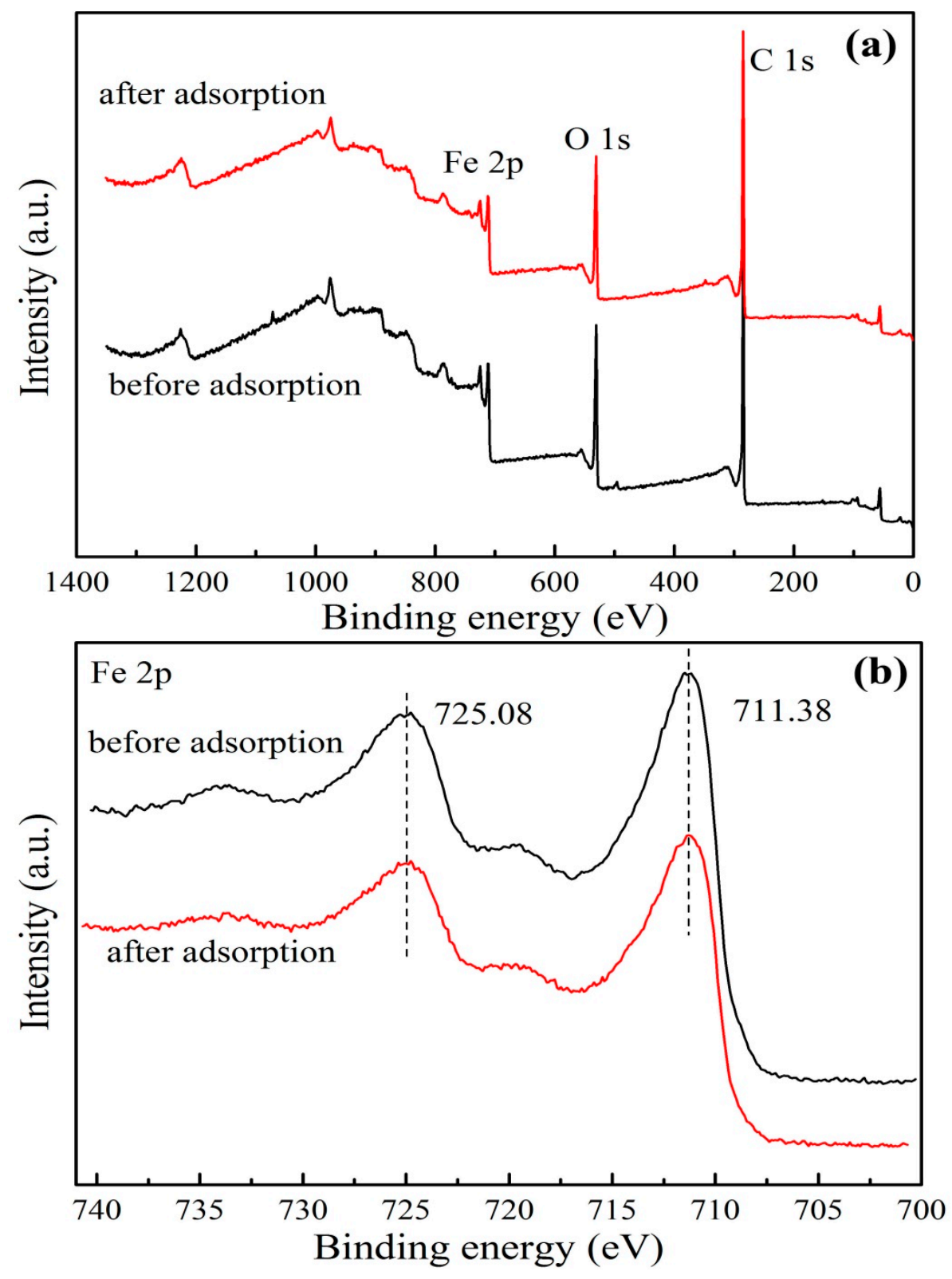

Figure 6. Cont. 

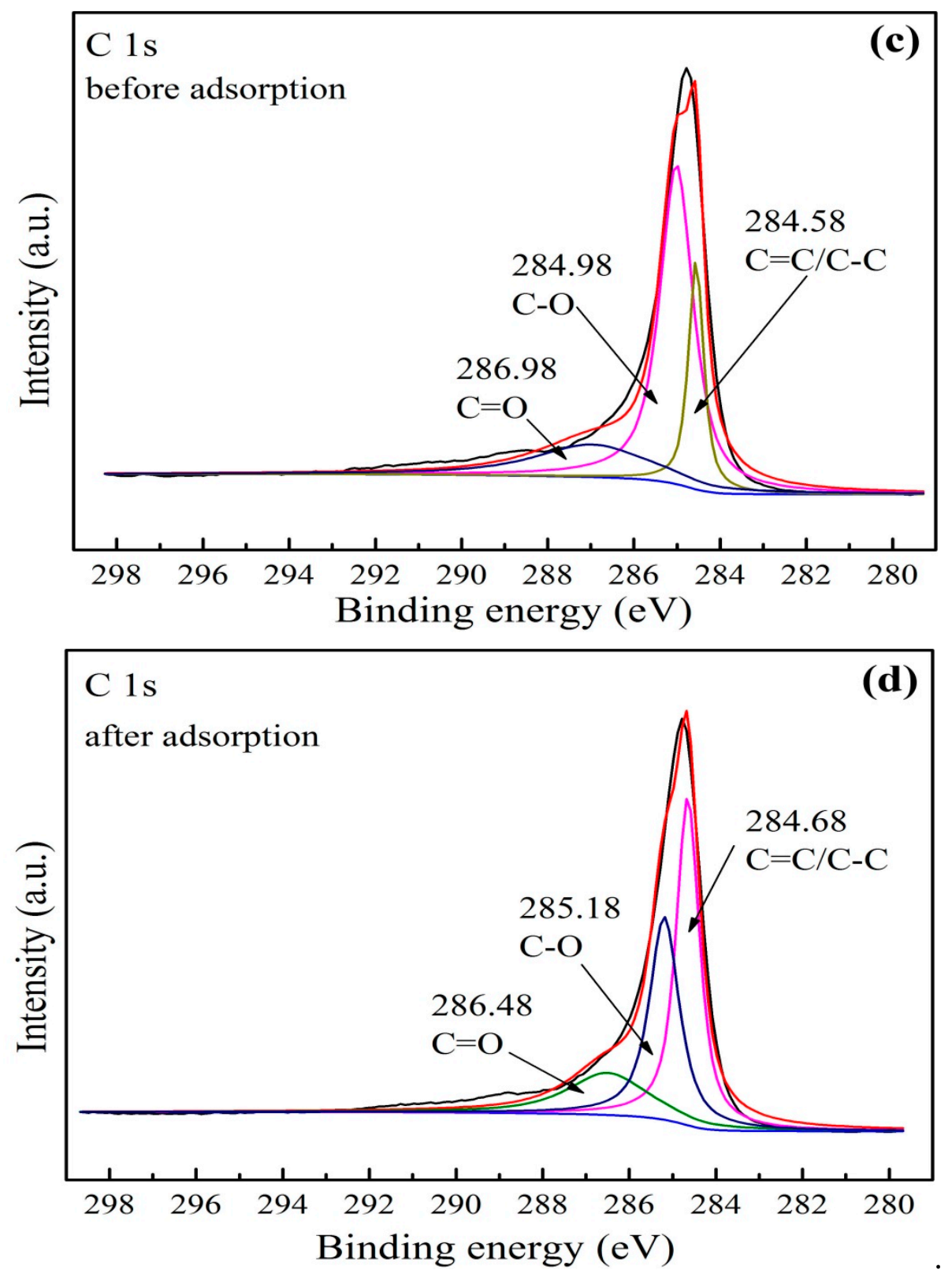

Figure 6. XPS spectra of: (a) the survey scan, and high-resolution scans of: (b) Fe2p, (c) C1s before adsorption, and (d) $\mathrm{C} 1 \mathrm{~s}$ after adsorption.

Table 1. Atomic percentages of $\mathrm{C}, \mathrm{O}, \mathrm{Fe}$, and $\mathrm{N}$.

\begin{tabular}{ccccc}
\hline \multirow{2}{*}{ Types } & \multicolumn{4}{c}{ Atomic \% } \\
\cline { 2 - 5 } & C 1s & O 1s & Fe 2p & N 1s \\
\hline Before adsorption & 66.54 & 22.04 & 7.7 & 0.47 \\
After adsorption & 71.19 & 19.32 & 5.19 & 0.87 \\
\hline
\end{tabular}

\subsection{Adsorption Kinetics}

The study of adsorption kinetics for PRO onto $\mathrm{GO} / \mathrm{Fe}_{3} \mathrm{O}_{4}$ was important for understanding the rate and mechanism of the adsorption process. The effect of contact time on adsorption was depicted in Figure 7. It can be seen that the reaction was very initially rapid and the adsorption capacity of PRO increased dramatically with time increasing. There were large surface area and a number of active sites on the surface of $\mathrm{GO} / \mathrm{Fe}_{3} \mathrm{O}_{4}$, which was good for the adsorption process. The high concentration of 
PRO in an aqueous solution was also attributed to the rapid adsorption. After 60 min, the adsorption rate gradually decreased. The reason for this trend was that the adsorption sites on the surface of the material were gradually occupied by PRO and the availability of the active sites was reduced, resulting in a slow adsorption rate. Moreover, the adsorbed $\mathrm{PRO}$ on the surface of $\mathrm{GO} / \mathrm{Fe}_{3} \mathrm{O}_{4} \mathrm{may}$ have also hindered the adsorption of $\mathrm{PRO}$ in the aqueous solution due to steric hindrance. With time increasing, the adsorption of $\mathrm{PRO}$ onto $\mathrm{GO} / \mathrm{Fe}_{3} \mathrm{O}_{4}$ was not significantly affected by the contact time and the adsorption tended to be in a stable state.

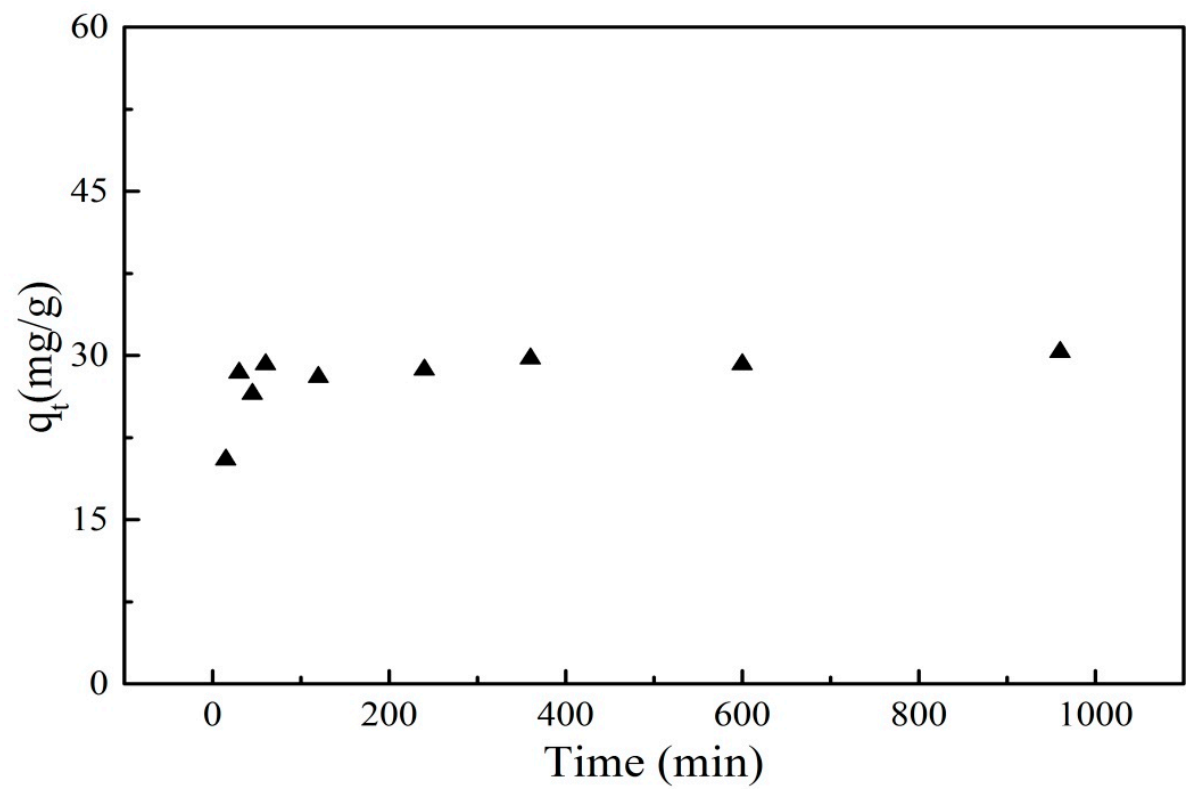

Figure 7. Effect of contact time on the adsorption of $\mathrm{PRO}$ onto $\mathrm{GO} / \mathrm{Fe}_{3} \mathrm{O}_{4}\left(\mathrm{C}_{0}=25 \mathrm{mg} / \mathrm{L}, V=20 \mathrm{~mL}, m\right.$ $=0.01 \mathrm{~g}, \mathrm{pH}=7.5)$.

Experimental data of the adsorption of $\mathrm{PRO}$ onto $\mathrm{GO} / \mathrm{Fe}_{3} \mathrm{O}_{4}$ was fitted using a pseudo-first-order kinetics model (Equation (2)) and a pseudo-second-order kinetics model (Equation (3)):

$$
\begin{gathered}
\ln \left(q_{e}-q_{t}\right)=\ln q_{e}-K_{1} t \\
\frac{t}{q_{t}}=\frac{1}{K_{2} q_{e}^{2}}+\frac{t}{q_{e}}
\end{gathered}
$$

where $q_{e}$ and $q_{t}$ are the amount of $\mathrm{PRO}$ adsorbed onto the $\mathrm{GO} / \mathrm{Fe}_{3} \mathrm{O}_{4}(\mathrm{mg} / \mathrm{g})$ at equilibrium and at time $\mathrm{t}(\mathrm{min})$, respectively; $K_{1}$ is the rate constant of pseudo-first-order adsorption (1/min); and $K_{2}$ is the constant of pseudo-second-order rate $(\mathrm{g} /(\mathrm{mg} \cdot \mathrm{min}))$. The kinetics curves were shown in Figure 8. The theoretical data and the fitted parameters were shown in Table 2.

Table 2. Kinetics parameters for the adsorption of $\mathrm{PRO}$ onto $\mathrm{GO} / \mathrm{Fe}_{3} \mathrm{O}_{4}$.

\begin{tabular}{ccccccc}
\hline \multirow{2}{*}{$\mathbf{q}_{\exp }(\mathbf{m g} / \mathbf{g})$} & \multicolumn{3}{c}{ Pseudo-First-Order Equation } & \multicolumn{3}{c}{ Pseudo-Second-Order Equation } \\
\cline { 2 - 7 } & $\mathbf{K}_{\mathbf{1}} \mathbf{( 1 / \mathbf { m i n } )}$ & $\mathbf{q}_{\text {cal }}(\mathbf{m g} / \mathbf{g})$ & $\mathbf{R}^{\mathbf{2}}$ & $\mathbf{K}_{\mathbf{2}}(\mathbf{g} /(\mathbf{m g} \cdot \mathbf{m i n}))$ & $\mathbf{q}_{\text {cal }}(\mathbf{m g} / \mathbf{g})$ & $\mathbf{R}^{\mathbf{2}}$ \\
\hline 30.340 & 0.0008 & 6.580 & 0.338 & 0.0045 & 30.303 & 0.999 \\
\hline
\end{tabular}



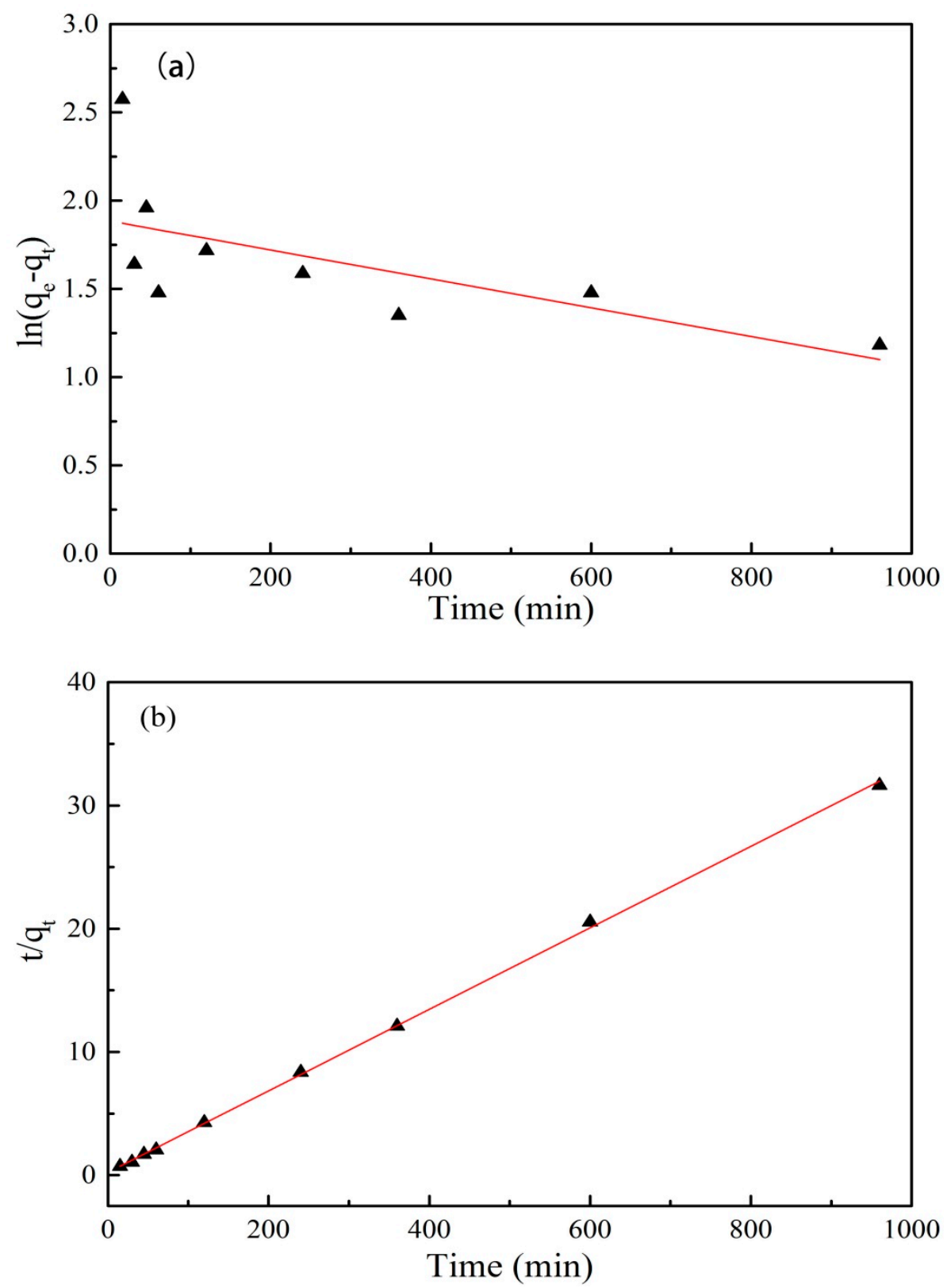

Figure 8. Adsorption kinetics curves of $\mathrm{PRO}$ onto $\mathrm{GO} / \mathrm{Fe}_{3} \mathrm{O}_{4}$ : (a) pseudo-first-order and (b) pseudo-second-order.

The correlation coefficient $\mathrm{R}^{2}$ for the pseudo-first-order kinetics model was 0.338 and the experimental data $(30.34 \mathrm{mg} / \mathrm{g})$ was quite different from the theoretical calculation data $(6.58 \mathrm{mg} / \mathrm{g})$. It can be judged that the model did not fit the experimental data well. The same result was also obtained from Figure 8a. Compared with the pseudo-first-order kinetics model, the correlation coefficient $\mathrm{R}^{2}$ for the pseudo-second-order kinetics model was higher $\left(R^{2}=0.999\right)$ and the experimental data was consistent with calculated values. It was observed directly from Figure $8 \mathrm{~b}$ that the adsorption of $\mathrm{PRO}$ onto $\mathrm{GO} / \mathrm{Fe}_{3} \mathrm{O}_{4}$ obeyed the pseudo-second-order kinetics model. The finding suggested that the control of the strong chemical reaction or surface complexion determined the adsorption rate.

\subsection{Adsorption Isotherm}

The adsorption isotherm experiment was conducted to get a better understanding of the adsorption mechanism of $\mathrm{PRO}$ onto $\mathrm{GO} / \mathrm{Fe}_{3} \mathrm{O}_{4}$. The relationship curve for the PRO equilibrium concentration and adsorption capacity was presented in Figure 9. It can be seen that the adsorption capacity 
increased linearly with the PRO initial concentration increasing at low concentrations, then showed a smaller increase when the concentration was further increased, and finally maintained a stable value. The results indicated that the PRO concentration was of great importance to the adsorption process. In the beginning, $\mathrm{GO} / \mathrm{Fe}_{3} \mathrm{O}_{4}$ showed a strong affinity to PRO due to the sufficient adsorption sites on the surface of adsorbents. The PRO transportation from the solvent to $\mathrm{GO} / \mathrm{Fe}_{3} \mathrm{O}_{4}$ surface was promoted by the increase of the PRO concentration. During the process of adsorption, the decrease of active sites on the surface of adsorbents led to the adsorption capacity being constant.

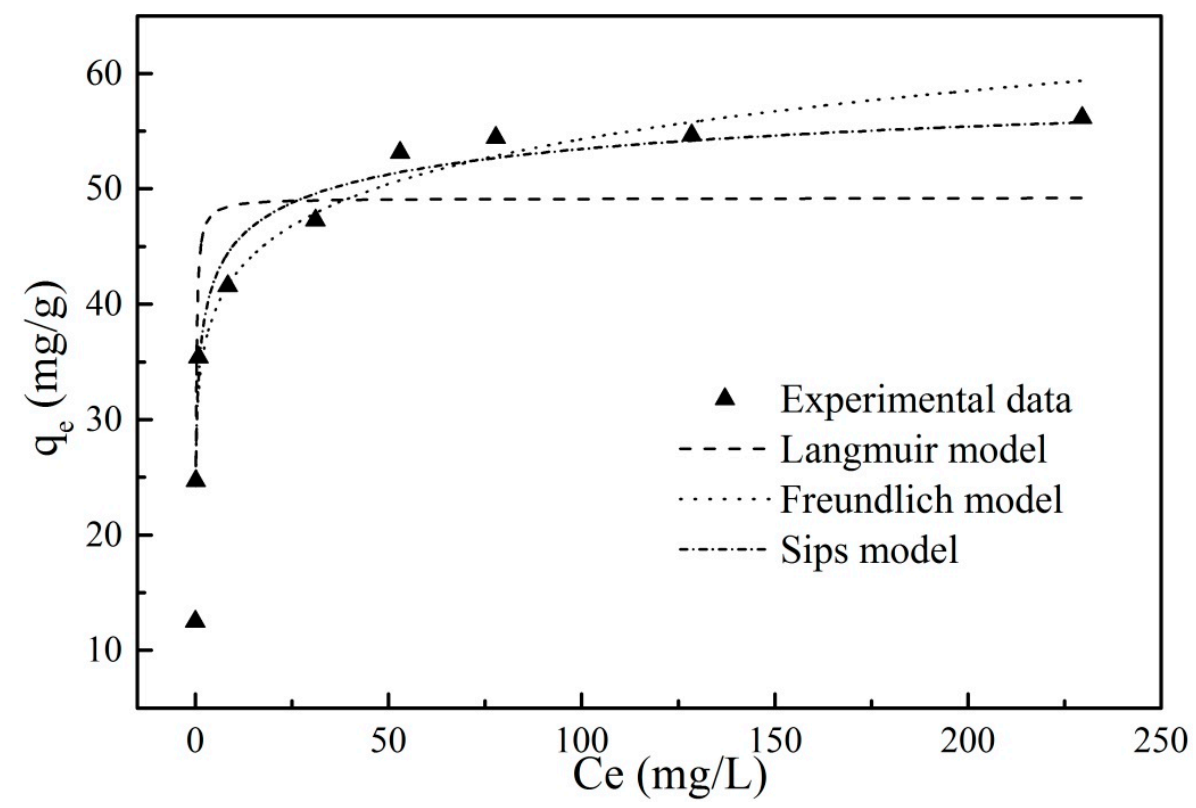

Figure 9. Langmuir, Freundlich, and Sips isotherm simulations for PRO onto GO/Fe $\mathrm{O}_{4}(t=24 \mathrm{~h}$, $V=20 \mathrm{~mL}, m=0.01 \mathrm{~g}, \mathrm{pH}=7.5)$.

Experimental data were fitted by Langmuir, Freundlich, and Sips isotherm models, respectively. The Langmuir model usually describes a monolayer adsorption, where the adsorption process occurs at homogeneous sites and the adsorbed molecules do not affect each other. The linear form of the Langmuir equation s expressed in Equation (4):

$$
\frac{1}{q_{e}}=\frac{1}{q_{m}}+\frac{1}{K_{L} q_{m} C_{e}}
$$

where $q_{m}(\mathrm{mg} / \mathrm{g})$ is the maximum amount of the adsorbed PRO per unit mass of $\mathrm{GO} / \mathrm{Fe}_{3} \mathrm{O}_{4} ; \mathrm{Ce}(\mathrm{mg} / \mathrm{L})$ is the equilibrium concentration of PRO onto the adsorbent; $q_{e}(\mathrm{mg} / \mathrm{g})$ is the amount of the adsorbed PRO at equilibrium; and $K_{L}$ is the Langmuir adsorption constant, which relates to the affinity and adsorption energy of the bonding sites.

The Freundlich model is an empirical relationship model that describes the adsorption process of heterogeneous surface. The Freundlich model is expressed in Equation (5):

$$
\log q_{e}=\frac{1}{n} \log C_{e}+\log K_{F}
$$

where $q_{e}(\mathrm{mg} / \mathrm{g})$ is the amount of the adsorbed PRO at equilibrium; $\mathrm{Ce}(\mathrm{mg} / \mathrm{L})$ is the equilibrium concentration of PRO onto the adsorbent; $K_{F}$ is Freundlich constant, which relates to the adsorption capacity and the adsorption strength; and $1 / n$ is the heterogeneity factor, where the value of $1 / n$ is between 0 and 1, and characterizes the effect of the concentration on the amount of adsorption. 
The Sips isotherm model was developed on the basis of the Langmuir and Freundlich models. The introduction of the third parameter gives it a wider range of applications. The Sips model is presented in Equation (6):

$$
q_{e}=\frac{q_{m}\left(b C_{e}\right)^{1 / n}}{1+\left(b C_{e}\right)^{1 / n}}
$$

where $q_{e}(\mathrm{mg} / \mathrm{g})$ is the amount of the adsorbed PRO at equilibrium; $q_{m}(\mathrm{mg} / \mathrm{g})$ is the maximum amount of the adsorbed PRO per unit mass of $\mathrm{GO} / \mathrm{Fe}_{3} \mathrm{O}_{4} ; \mathrm{Ce}(\mathrm{mg} / \mathrm{L})$ is the equilibrium concentration of $\mathrm{PRO}$ onto the adsorbent; $1 / n$ is the heterogeneity factor, where the value for $1 / n$ getting closer to 1 indicates a relatively homogenous adsorbent surface; and $b(\mathrm{~L} / \mathrm{mg})$ is the median association constant.

Experimental data were fitted using the three isotherm models described and the obtained curves were shown in Figure 9. The fitting results were shown in Table 3. It was clear that the Langmuir adsorption isotherms had the lowest correlation coefficients (0.857) among the three models, which indicated that the adsorption process was not a single monolayer adsorption onto $\mathrm{GO} / \mathrm{Fe}_{3} \mathrm{O}_{4}$ and the distribution of sites on the adsorbent was not homogeneous. The findings for this experiment were consistent with the fitting parameter values of the Freundlich model. Compared to the Langmuir model, the Freundlich adsorption isotherm had a higher $\mathrm{R}^{2}$ value (0.961). The value of $n$ was between 1 and 10, indicating that the occurrence of the adsorption process was favorable. When the PRO concentration was low, the experimental data were better fitted with the theoretical data calculated by the Freundlich model. However, the Freundlich adsorption isotherm deviated from the experimental data as the PRO concentration increased. The Sips adsorption isotherm was more appropriate for the adsorption of $\mathrm{PRO}$ onto $\mathrm{GO} / \mathrm{Fe}_{3} \mathrm{O}_{4}$ and the $\mathrm{R}^{2}$ value (0.983) was the highest amongst the three involved models. For the Sips isotherm, $1 / n$ is less than 1 , indicating a heterogeneous adsorbent.

Table 3. The parameters for Langmuir, Freundlich, and Sips isotherm models of PRO adsorption onto $\mathrm{GO} / \mathrm{Fe}_{3} \mathrm{O}_{4}$.

\begin{tabular}{ccccccccccc}
\hline \multicolumn{3}{c}{ Langmuir Equation } & \multicolumn{3}{c}{ Freundlich Equation } & \multicolumn{5}{c}{ Sips Equation } \\
\hline $\begin{array}{c}\mathbf{q}_{\mathbf{m}} \\
(\mathbf{m g} / \mathbf{g})\end{array}$ & $\begin{array}{c}\mathbf{K}_{\mathbf{L}} \\
(\mathbf{L} / \mathbf{m g})\end{array}$ & $\mathbf{R}^{\mathbf{2}}$ & $\begin{array}{c}\mathbf{K}_{\mathbf{F}} \\
(\mathbf{m g} / \mathbf{g})\end{array}$ & $\mathbf{n}$ & $\mathbf{R}^{2}$ & $\begin{array}{c}\mathbf{q}_{\mathbf{m}} \\
(\mathbf{m g} / \mathbf{g})\end{array}$ & $\begin{array}{c}\mathbf{b} \\
(\mathbf{L} / \mathbf{m g})\end{array}$ & $\mathbf{n}$ & $\mathbf{R}^{\mathbf{2}}$ \\
\hline 49.213 & 7.629 & 0.857 & 33.123 & 9.317 & 0.961 & 66.225 & 0.322 & 3.443 & 0.983 \\
\hline
\end{tabular}

\subsection{Effect of $p H$}

The $\mathrm{pH}$ of the solution determines not only the surface charge of the adsorbent but also the existing form of the adsorbate. Therefore, the effect of $\mathrm{pH}$ on the adsorption process was investigated and the results are given in Figure 10a. PRO was positively charged when the $\mathrm{pH}$ of the solution was less than 9.5. At a $\mathrm{pH}$ below 5, the adsorption capacity of $\mathrm{PRO}$ onto $\mathrm{GO} / \mathrm{Fe}_{3} \mathrm{O}_{4}$ increased rapidly, which was ascribed to an increasing of $\mathrm{H}^{+}$concentration with $\mathrm{pH}$ increasing. Under a strong acid condition, a high concentration of $\mathrm{H}^{+}$occupied the adsorption sites on the surface of the adsorbent. The adsorption of PRO was suppressed due to the competitive adsorption of $\mathrm{H}^{+}$. However, the adsorption inhibition of $\mathrm{PRO}$ onto $\mathrm{GO} / \mathrm{Fe}_{3} \mathrm{O}_{4}$ by $\mathrm{H}^{+}$was weakened as the $\mathrm{pH}$ increased. It can be seen from Figure 5 that $\mathrm{GO} / \mathrm{Fe}_{3} \mathrm{O}_{4}$ was positively charged and there was an electrostatic repulsion between the adsorbent and PRO, which may have been responsible for the lower adsorption capacity of PRO under acidic conditions. When the $\mathrm{pH}$ was further increased, a slowly increasing trend of adsorption capacity was presented. The hindrance of $\mathrm{H}^{+}$was weaker. Furthermore, $\mathrm{GO} / \mathrm{Fe}_{3} \mathrm{O}_{4}$ was negatively charged when $\mathrm{pH}>6$. Thus, there was an electrostatic attraction between PRO and the adsorbent, which contributed to the adsorption of PRO. As shown in Figure 10b, the $\mathrm{pH}$ values after the reaction were higher than those before the reaction when the $\mathrm{pH}$ was below 7 . The decrease of the $\mathrm{H}^{+}$concentration suggested that $\mathrm{H}^{+}$participated in the adsorption process of PRO. When the $\mathrm{pH}$ was increased from 8 to 9.5, the adsorption capacity increased rapidly and reached a maximum adsorption capacity. Adsorption competition of $\mathrm{H}^{+}$was weak, and other forces, like hydrogen bonding and $\pi-\pi$ interactions between 
PRO and the adsorbent, may have dominated the adsorption process. When $\mathrm{pH}>\mathrm{pKa}$, the amino group of PRO was deprotonated. PRO existed as a neutral molecule. The weakening of the electrostatic attraction led to a slow decrease of the adsorption capacity. The adsorption of PRO onto GO/Fe $3 \mathrm{O}_{4}$ had a similar adsorption tendency to that on GO (Figure S1 in the Supplementary Materials), indicating that the adsorption mechanism of $\mathrm{GO} / \mathrm{Fe}_{3} \mathrm{O}_{4}$ mainly depended on $\mathrm{GO}$.
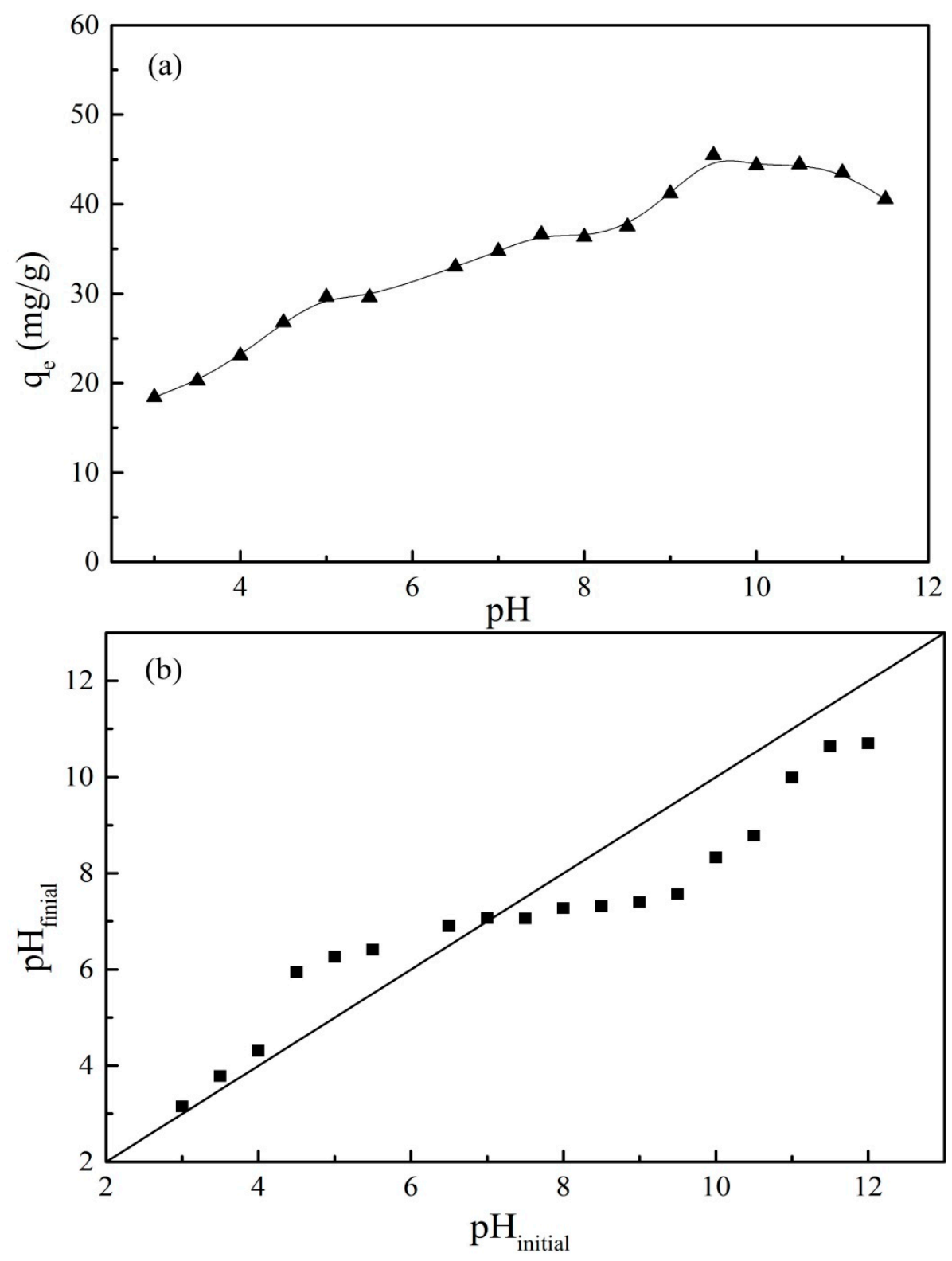

Figure 10. (a) Effect of $\mathrm{pH}$ on the adsorption of $\mathrm{PRO}$ onto $\mathrm{GO} / \mathrm{Fe}_{3} \mathrm{O}_{4}$, and (b) the variation tendency of $\mathrm{pH}$ after the adsorption equilibrium was reached $\left(C_{0}=25 \mathrm{mg} / \mathrm{L}, V=20 \mathrm{~mL}, m=0.01 \mathrm{~g}, t=24 \mathrm{~h}\right)$.

\subsection{Material Stability}

To determine the stability of the material, the amount of Fe in the solution was determined after the adsorption equilibrium was reached. Figure 11 showed the amount of Fe leaching at different $\mathrm{pH}$ levels. When the $\mathrm{pH}$ was between 4 and 9, the Fe element was hardly leached, but was easily leached under strong acid or alkali conditions. The results suggested that $\mathrm{GO} / \mathrm{Fe}_{3} \mathrm{O}_{4}$ can be used in a wide range of neutral water. 


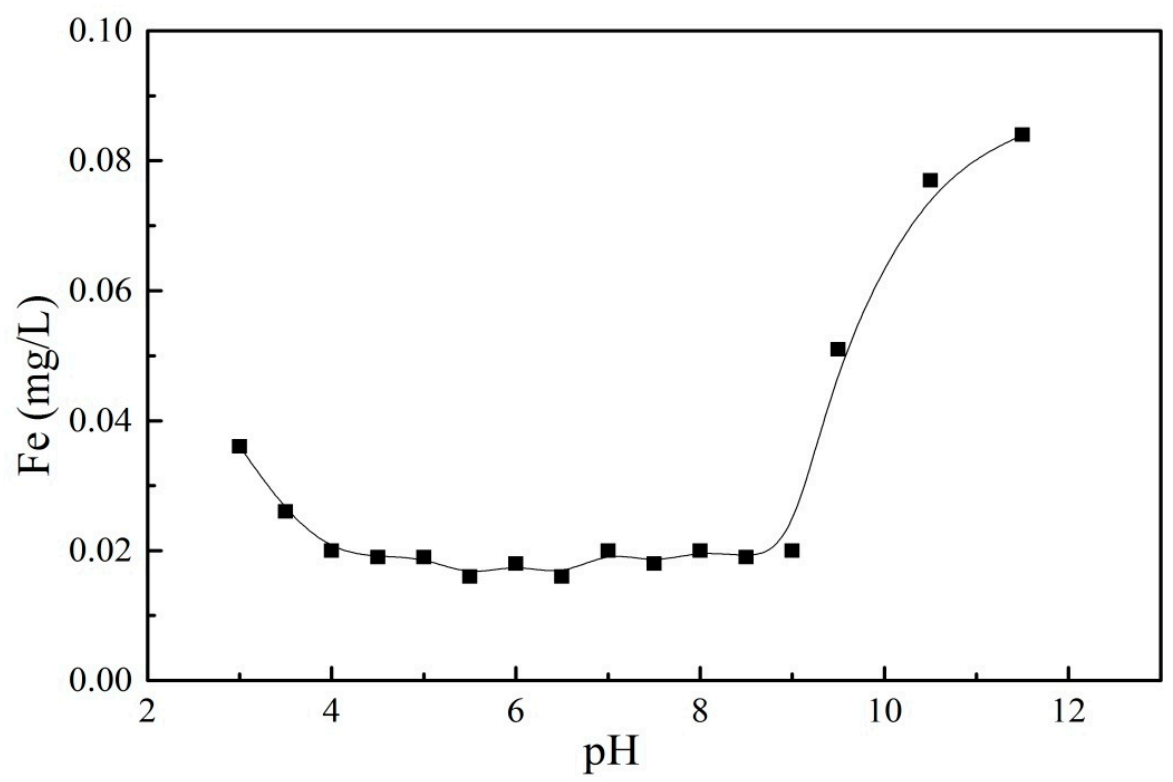

Figure 11. The leaching amount of $\mathrm{Fe}$ on $\mathrm{GO} / \mathrm{Fe}_{3} \mathrm{O}_{4}$ at different $\mathrm{pH}$ levels.

\subsection{Effect of $H A$}

HA, widely distributed in water, can interact with organic matter. HA has an important influence on the migration behavior of PRO in the environment. The effect of HA on the adsorption of PRO onto $\mathrm{GO} / \mathrm{Fe}_{3} \mathrm{O}_{4}$ under different $\mathrm{HA}$ concentrations is shown in Figure 12. The presence of HA had a little effect on the adsorption of $\mathrm{PRO}$ onto $\mathrm{GO} / \mathrm{Fe}_{3} \mathrm{O}_{4}$. The adsorption capacity dropped slightly and then remained constant. HA surface was negatively charged as the $\mathrm{pH}$ of the solution was above 2 [30]. The $\mathrm{pH}$ condition for this experiment was 7.5. Thus, both $\mathrm{HA}$ and $\mathrm{GO} / \mathrm{Fe}_{3} \mathrm{O}_{4}$ were negatively charged. The electrostatic repulsion between them led to HA tending to be stable in the aqueous solution rather than being adsorbed onto the $\mathrm{GO} / \mathrm{Fe}_{3} \mathrm{O}_{4}$ surface. The electrostatic attraction between the cationic PRO and the negatively charged HA caused the PRO adsorbed onto $\mathrm{GO} / \mathrm{Fe}_{3} \mathrm{O}_{4}$ to desorb from its surface into the aqueous solution, which hindered the adsorption of $\mathrm{PRO}$ onto $\mathrm{GO} / \mathrm{Fe}_{3} \mathrm{O}_{4}$. The initial concentration of PRO in this experiment was small, thus the solubilization was not significant.

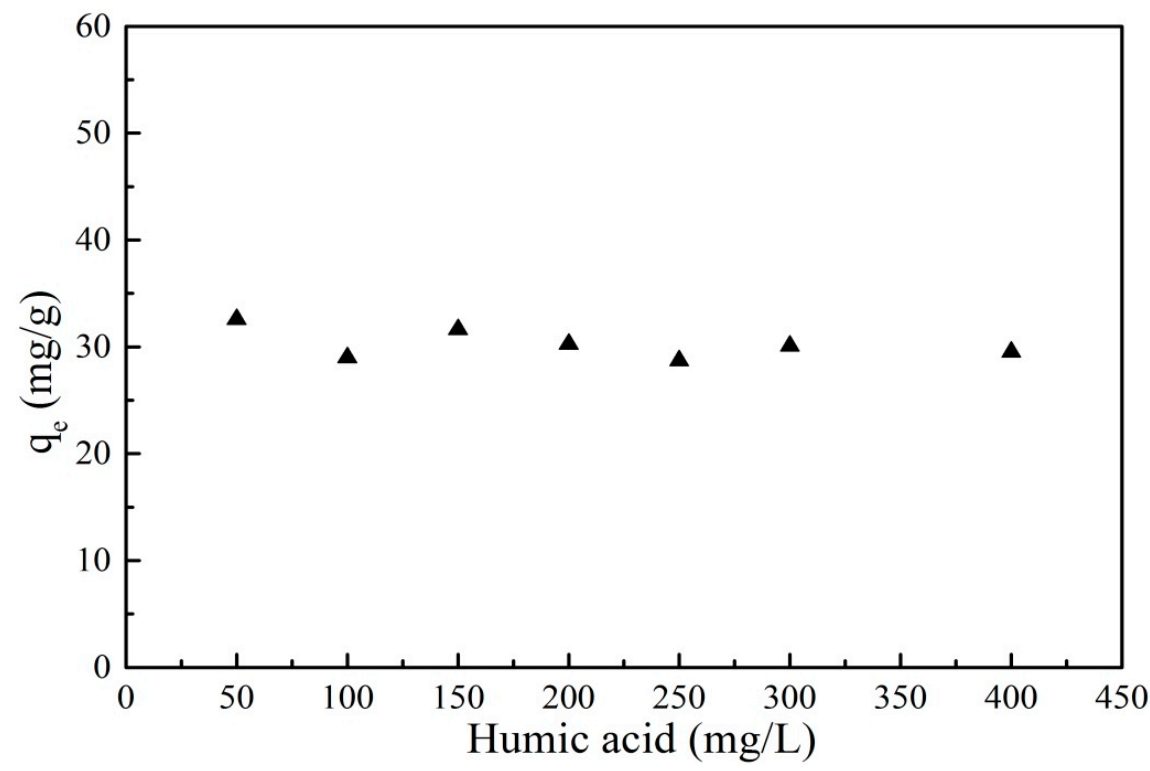

Figure 12. Effect of humic acid for PRO onto GO/Fe $\mathrm{O}_{4}\left(C_{0}=25 \mathrm{mg} / \mathrm{L}, V=20 \mathrm{~mL}, m=0.01 \mathrm{~g}, t=24 \mathrm{~h}\right.$, $\mathrm{pH}=7.5)$. 


\subsection{Comparison of $\mathrm{GO} / \mathrm{Fe}_{3} \mathrm{O}_{4}$ with other Adsorbents}

To further evaluate the performance of the adsorbent, the adsorption capacity of $\mathrm{GO} / \mathrm{Fe}_{3} \mathrm{O}_{4}$ was compared to other adsorbents. The adsorption capacity of PRO onto GO was $67 \mathrm{mg} / \mathrm{g}$ [17], and the adsorption capacity of $\mathrm{GO} / \mathrm{Fe}_{3} \mathrm{O}_{4}$ was lower relatively due to the introduction of $\mathrm{Fe}_{3} \mathrm{O}_{4}$ nanoparticles. However, the loading of $\mathrm{Fe}_{3} \mathrm{O}_{4}$ greatly reduced the manufacturing cost of the adsorbent and facilitated the separation of GO from water. In the previous work, the adsorption of PRO onto acidified attapulgite $(48.05 \mathrm{mg} / \mathrm{g})$, chitosan-modified attapulgite $(26.38 \mathrm{mg} / \mathrm{g})$, and coupling-agent-modified attapulgite $\left(24.56 \mathrm{mg} / \mathrm{g}\right.$ ) were also studied [16]. It is obvious that the adsorption capacity of $\mathrm{PRO}$ onto $\mathrm{GO} / \mathrm{Fe}_{3} \mathrm{O}_{4}$ was higher than the above adsorbents. In summary, $\mathrm{GO} / \mathrm{Fe}_{3} \mathrm{O}_{4}$ could be used as a promising adsorbent to remove PRO from water.

\section{Conclusions}

A nanomagnetic material $\mathrm{GO} / \mathrm{Fe}_{3} \mathrm{O}_{4}$ was prepared facilely and investigated regarding its ability to remove contaminant PRO from water via adsorption. All the characterization results indicated that the prepared adsorbent was successfully synthesized and easily recovered from the water by an external magnetic field. The kinetics experimental data were fitted well with the pseudo-second-order kinetics, showing that the adsorption process was controlled by chemical reactions or surface complexation. The high correlation coefficient of the Sips model showed multilayer adsorption and the heterogeneous adsorbent surface. Electrostatic attraction, hydrogen bonding, and $\pi-\pi$ interactions all contributed to the adsorption process of $\mathrm{PRO}$ onto $\mathrm{GO} / \mathrm{Fe}_{3} \mathrm{O}_{4}$. The adsorption process was $\mathrm{pH}$-dependent and slightly inhibited by HA. All experimental results revealed that $\mathrm{GO} / \mathrm{Fe}_{3} \mathrm{O}_{4}$ can be used as an effective adsorbent for the removal of PRO from water.

Supplementary Materials: The following are available online at http://www.mdpi.com/2079-4991/9/10/1429/s1, Figure S1: Effect of $\mathrm{pH}$ on the adsorption of GO for PRO $\left(C_{0}=25 \mathrm{mg} / \mathrm{L}, V=40 \mathrm{~mL}, m=0.01 \mathrm{~g}, t=24 \mathrm{~h}\right)$.

Author Contributions: Y.D. designed the experiments. Y.L., X.T., and M.C. performed the experiments. Y.L., X.G., W.N., and S.L. analyzed the data. Y.D., Y.L., and D.H. produced the figures and tables. Y.D. and Y.L. wrote the manuscript.

Funding: This research was funded by National Nature Science Foundation of China (grant no. 21806128), the Basic Research Plan of Natural Science in Shaanxi Province-General Project (Youth) (2018JQ2030), the Research Cultivation Fund of Xi'an University of Science and Technology (201720), the Doctoral Scientific Research Foundation of Xi'an University of Science and Technology (2016ZX217), and the Scientific Research Program-Shaanxi Provincial Education Department (17JK0507, 17JK0492).

Conflicts of Interest: The authors declare no conflict of interest.

\section{References}

1. Lee, X.J.; Hiew, B.; Lai, K.; Lee, L.; Gan, S.; Thangalazhy-Gopakumar, S.; Rigby, S. Review on graphene and its derivatives: Synthesis methods and potential industrial implementation. J. Taiwan Inst. Chem. E 2019, 98, 163-180. [CrossRef]

2. Shen, Y.; Chen, B. Sulfonated Graphene Nanosheets as a Superb Adsorbent for Various Environmental Pollutants in Water. Environ. Sci. Technol. 2015, 49, 7364-7372. [CrossRef]

3. Huang, D.; Xu, B.; Wu, J.; Brookes, C.P.; Xu, J. Adsorption and desorption of phenanthrene by magnetic graphene nanomaterials from water: Roles of $\mathrm{pH}$, heavy metal ions and natural organic matter. Chem. Eng. J. 2019, 368, 390-399. [CrossRef]

4. Lujanienè, G.; Šemčuk, S.; Kulakauskaitè, I.; Mažeika, K.; Valiulis, D.; Juškènas, R.; Tautkus, S. Sorption of radionuclides and metals to graphene oxide and magnetic graphene oxide. J. Radioanal Nucl. Chem. 2016, 307, 2267-2275. [CrossRef]

5. Wei, H.; Yang, W.; Xi, Q.; Chen, X. Preparation of $\mathrm{Fe}_{3} \mathrm{O}_{4} @$ graphene oxide core-shell magnetic particles for use in protein adsorption. Mater. Lett. 2012, 82, 224-226. [CrossRef]

6. Wang, C.; Zhou, J.; Chu, L. Chlorine-functionalized reduced graphene oxide for methylene blue removal. RSC Adv. 2015, 5, 52466-52472. [CrossRef] 
7. Wei, M.; Chai, H.; Cao, Y.; Jia, D. Sulfonated graphene oxide as an adsorbent for removal of $\mathrm{Pb}^{2+}$ and methylene blue. J. Colloid Interf. Sci. 2018, 524, 297-305. [CrossRef] [PubMed]

8. Khan, A.; Wang, J.; Li, J.; Wang, X.; Chen, Z.; Alsaedi, A.; Hayat, T.; Chen, Y.; Wang, X. The role of graphene oxide and graphene oxide-based nanomaterials in the removal of pharmaceuticals from aqueous media: A review. Environ. Sci. Pollut. Res. 2017, 24, 7938-7958. [CrossRef] [PubMed]

9. Liu, J.; Wong, M. Pharmaceuticals and personal care products (PPCPs): A review on environmental contamination in China. Environ. Int. 2013, 59, 208-224. [CrossRef] [PubMed]

10. Yang, H.; An, T.; Li, G.; Song, W.; Cooper, J.W.; Luo, H.; Guo, X. Photocatalytic degradation kinetics and mechanism of environmental pharmaceuticals in aqueous suspension of $\mathrm{TiO}_{2}$ : A case of $\beta$-blockers. J. Hazard Mater. 2010, 179, 834-839. [CrossRef] [PubMed]

11. Maszkowska, J.; Stolte, S.; Kumirska, J.; Łukaszewicz, P.; Mioduszewska, K.; Puckowski, A.; Caban, M.; Wagil, M.; Stepnowski, P.; Białk-Bielińska, A. Beta-blockers in the environment: Part I. Mobility and hydrolysis study. Sci. Total Environ. 2014, 493, 1112-1121. [CrossRef] [PubMed]

12. Orta, M.; Martín, J.; Medina-Carrasco, S.; Santos, L.J.; Aparicio, I.; Alonso, E. Adsorption of propranolol onto montmorillonite: Kinetic, isotherm and pH Studies. Appl. Clay Sci. 2019, 173, 107-114. [CrossRef]

13. Ali, I.; Alothmanb, A.Z.; Alwarthan, A. Uptake of propranolol on ionic liquid iron nanocomposite adsorbent: Kinetic, thermodynamics and mechanism of adsorption. J. Mol. Liq. 2017, 236, 205-213. [CrossRef]

14. Maszkowska, J.; Stolte, S.; Kumirska, J.; Łukaszewicz, P.; Mioduszewska, K.; Puckowski, A.; Caban, M.; Wagil, M.; Stepnowski, P.; Białk-Bielińska, A. Beta-blockers in the environment: Part II. Ecotoxicity study. Sci. Total. Environ. 2014, 493, 1122-1126. [CrossRef] [PubMed]

15. Yamamoto, H.; Nakamura, Y.; Moriguchi, S.; Nakamura, Y.; Honda, Y.; Tamura, I.; Hirata, Y.; Hayashi, A.; Sekizawa, J. Persistence and partitioning of eight selected pharmaceuticals in the aquatic environment: Laboratory photolysis, biodegradation, and sorption experiments. Water Res. 2009, 43, 351-362. [CrossRef]

16. Deng, Y.; Wu, F.; Liu, B.; Hu, X.; Sun, C. Sorptive removal of $\beta$-blocker propranolol from aqueous solution by modified attapulgite: Effect factors and sorption mechanisms. Chem. Eng. J. 2011, 174, 571-578. [CrossRef]

17. Kyzas, G.Z.; Koltsakidou, A.; Nanaki, S.G.; Bikiaris, D.N.; Lambropoulou, D.A. Removal of beta-blockers from aqueous media by adsorption onto graphene oxide. Sci. Total Environ. 2015, 537, 411-420. [CrossRef] [PubMed]

18. Cao, X.T.; Showkat, M.A.; Kang, I.; Gal, Y.S.; Lim, K.T. $\beta$-Cyclodextrin Multi-Conjugated Magnetic Graphene Oxide as a Nano-Adsorbent for Methylene Blue Removal. J. Nanosci. Nanotechnol. 2016, 16, 1521-1525. [CrossRef]

19. Peng, W.; Li, H.; Liu, Y.; Song, S. A review on heavy metal ions adsorption from water by graphene oxide and its composites. J. Mol. Liq. 2017, 230, 496-504. [CrossRef]

20. Peng, G.W.; Ding, D.X.; Xiao, F.Z.; Wang, X.L.; Hun, N.; Wang, Y.D.; Dai, Y.M.; Cao, Z. Adsorption of uranium ions from aqueous solution by amine-group functionalized magnetic $\mathrm{Fe}_{3} \mathrm{O}_{4}$ nanoparticle. J. Radioanal Nucl. Chem. 2014, 301, 781-788. [CrossRef]

21. Hashemian, S.; Saffari, H.; Ragabion, S. Adsorption of Cobalt (II) from Aqueous Solutions by $\mathrm{Fe}_{3} \mathrm{O}_{4} / \mathrm{Bentonite}$ Nanocomposite. Water Air. Soil. Pollut. 2015, 226, 2212. [CrossRef]

22. McCoy, M.T.; Turpin, G.; Teo, M.B.; Tabor, F.R. Graphene oxide: A surfactant or particle? Curr. Opin. Colloid. Int. 2019, 39, 98-109. [CrossRef]

23. Kadam, A.A.; Jang, J.; SungLee, D. Facile synthesis of pectin-stabilized magnetic graphene oxide Prussian blue nanocomposites for selective cesium removal from aqueous solution. Bioresour. Technol. 2016, 216, 391-398. [CrossRef]

24. Miao, J.; Wang, F.; Chen, Y.; Zhu, Y.; Zhou, Y.; Zhang, S. The adsorption performance of tetracyclines on magnetic graphene oxide: A novel antibiotics absorbent. Appl. Surf. Sci. 2019, 475, 549-558. [CrossRef]

25. He, F.; Fan, J.; Ma, D.; Zhang, L.; Leung, C.; Chan, L.H. The attachment of $\mathrm{Fe}_{3} \mathrm{O}_{4}$ nanoparticles to graphene oxide by covalent bonding. Carbon 2010, 48, 3139-3144. [CrossRef]

26. Huang, D.; Wu, J.; Wang, L.; Liu, X.; Meng, J.; Tang, X.; Tang, C.; Xu, J. Novel insight into adsorption and co-adsorption of heavy metal ions and an organic pollutant by magnetic graphene nanomaterials in water. Chem. Eng. J. 2019, 358, 1399-1409. [CrossRef]

27. Deng, Y.; Li, Y.; Nie, W.; Gao, X.; Zhang, L.; Yang, P.; Tan, X. Fast Removal of Propranolol from Water by Attapulgite/Graphene Oxide Magnetic Ternary Composites. Materials 2019, 12, 924. [CrossRef] 
28. Othman, H.N.; Alias, H.N.; Shahruddin, Z.M.; Bakar, N.; Him, N.; Lau, W. Adsorption kinetics of methylene blue dyes onto magnetic graphene oxide. J. Environ. Chem. Eng. 2018, 6, 2803-2811. [CrossRef]

29. Zhao, D.; Zhu, H.; Wu, C.; Feng, S.; Alsaedi, A.; Hayat, T.; Chen, C. Facile synthesis of magnetic $\mathrm{Fe}_{3} \mathrm{O}_{4}$ /graphene composites for enhanced U(VI) sorption. Appl. Surf. Sci. 2018, 444, 691-698. [CrossRef]

30. Xu, B.; Lian, Z.; Liu, F.; Yu, Y.; He, Y.; Brookes, C.P.; Xu, J. Sorption of pentachlorophenol and phenanthrene by humic acid-coated hematite nanoparticles. Environ. Pollut. 2019, 248, 929-937. [CrossRef]

(C) 2019 by the authors. Licensee MDPI, Basel, Switzerland. This article is an open access article distributed under the terms and conditions of the Creative Commons Attribution (CC BY) license (http://creativecommons.org/licenses/by/4.0/). 